\title{
Physicochemical and rheological characterization of different Carnoy's solutions applied in oral and maxillofacial surgery
}

\author{
Francisco Samuel Rodrigues Carvalho ${ }^{1,2}$ (D) | Victor Pinheiro Feitosa ${ }^{3}$ | \\ Said Gonçalves da Cruz Fonseca ${ }^{4}$ | Thiago Dias de Vasconcelos Araújo ${ }^{5}$ | \\ Eduardo Costa Studart Soares ${ }^{6}$ | Cristiane Sá Roriz Fonteles ${ }^{7}$ | Thyciana Rodrigues Ribeiro ${ }^{7}$ | \\ Fábio Wildson Gurgel Costa ${ }^{8}$
}

\footnotetext{
${ }^{1}$ Division of Oral and Maxillofacial Surgery, Federal University of Ceará, Fortaleza, Brazil

${ }^{2}$ Division of Oral and Maxillofacial Morphology and Oral and Maxillofacial Surgery, UNIFOR, Fortaleza, Brazil

${ }^{3}$ Paulo Picanço School of Dentistry, Fortaleza, Ceará, Brazil

${ }^{4}$ Division of Pharmacology Sciences, Federal University of Ceará, Fortaleza, Brazil

${ }^{5}$ Division of Pharmacology, Federal University of Ceará, Fortaleza, Brazil

${ }^{6}$ Division of Oral and Maxillofacial Surgery, Walter Cantídio University Hospital, Federal University of Ceará, Fortaleza, Brazil

${ }^{7}$ School of Dentistry, Federal University of Ceará, Fortaleza, Brazil

${ }^{8}$ Division of Oral Radiology, Walter Cantídio University Hospital, Federal University of Ceará, Fortaleza, Brazil

\section{Correspondence}

Francisco Samuel Rodrigues Carvalho, Division of Oral and Maxillofacial Surgery, Federal University of Ceará, Rua Monsenhor Furtado, Rodolfo Teófilo, Fortaleza, Ceará CEP: 60.430-350, Brazil. Email: samuelcarvalho@unifor.br; samuel.rcarvalho@gmail.com
}

\begin{abstract}
Carnoy's solution has been widely undertaken as adjunctive therapy for benign odontogenic tumors. Although its outcomes were highly investigated, little information is available regarding its mechanism of action and the role of chloroform in composition. The aim of this study was to characterize Carnoy's solution (with and without chloroform) in order to survey its physicochemical and pharmacological properties. UV/Vis spectroscopy, Raman microspectroscopy, viscosity assessment, $\mathrm{pH}$ analysis, and ion $\left(\mathrm{Fe}^{3+}\right)$ concentration were studied. All solutions were prepared by the same operator and assayed at each 7 days within a 4-week period. All solutions depicted acidic $\mathrm{pH}$ whereas the viscosity was increased by the addition of chloroform. Starting in the seventh day after preparation, solutions with chloroform showed iron precipitation when nonfiltered. Carnoy's solution without chloroform was stable during the survey period as evidenced by Raman spectroscopy. In conclusion, Carnoy's solution possesses an acidic characteristic, it is stable when stored at room temperature, and precipitates iron salts when in the presence of chloroform in a nonfiltered solution. The chloroform increases the viscosity of the solution and makes its pH slightly more acidic when compared to the Carnoy's solution without chloroform. Raman spectroscopy favored the evaluation of components' stability in solutions by using the spectra analysis and the established correlations between the peaks in different periods.
\end{abstract}

\section{KEYWORDS}

Carnoy's solution, chloroform, oral surgery, Raman spectroscopy

\section{1 | INTRODUCTION}

The maxillofacial region may be affected by a variety of benign lesions but locally invasive with a high incidence of recurrences such as ameloblastoma, odontogenic myxoma, and keratocystic odontogenic tumor. Conservative treatment might lead to recurrence, and radical approach could result in aesthetic-functional sequels. ${ }^{[1,2]}$ Thus, 
complementary therapies to the surgery are largely employed in the literature in order to reduce recurrence rate and potential damages. ${ }^{[2]}$ Within the different modalities of surgery treatments, there is no method associated with zero recurrence rate. ${ }^{[3]}$ Regarding these therapies, Carnoy's solution has been highlighted principally for keratocystic odontogenic tumor, ${ }^{[1-17]}$ once lowest recurrence rates were found for surgery resection method followed by enucleation with adjunctive use of Carnoy's solution. ${ }^{[3]}$

In 1886, Jean Baptiste Carnoy improved the fixation solution of Clarke (1851) for botanic investigations, thereby proposing a mixture of absolute ethanol, chloroform, and glacial acetic acid in 6:3:1 ratio, respectively. This solution is a fixation agent of rapid activity, useful for visualization of cell core, proteins, and glycogen but unsuitable for lipids. ${ }^{[18,19]}$ After almost half century from this invention, the first use in surgery occurred by Zollinger and Moritz. ${ }^{[20]}$ Authors surveyed the effect of different necrobiotic agents for cysts in dog brains. Carnoy's solution with ferric chloride addition was assessed in order to enclose hemostatic features for the treatment. ${ }^{[20]}$ This combination provided moderate tissue penetration, rapid local fixation of cystic surrounding cells and optimal hemostasis. In 1933, Cutler and Zollinger employed this solution for clinical treatment of patients with cysts and fistulas. ${ }^{[21]}$ Voorsmit et al. ${ }^{[4]}$ published the first report of the adjunctive usage of Carnoy's solution for surgical treatment of odontogenic keratocyst, which presented, until that period, high incidence of recurrence. ${ }^{[4]}$ According to the authors, the application of Carnoy's solution is based on three aspects for such odontogenic lesions: Cyst epithelium is fragile and its remnants might remain in bone cavity; the occurrence of remaining microcysts or epithelium islands, which were on the walls of initial cyst; and development of new keratocysts arising from derivations from basal layer of oral epithelium. ${ }^{[4]}$ Therefore, Carnoy's solution warrants reduction of lesions, less fragility, improvement of complete enucleation, and adequate local hemostasis. ${ }^{[22]}$

A wide variety of treatments has been suggested for the therapy of odontogenic tumors, encompassing surgical approaches (enucleation, curettage, peripheral osteotomy, cryosurgery, etc.) isolated or combined with conventional Carnoy's solution or the modified one (without chloroform). ${ }^{[4,12,23-25]}$ It has been demonstrated that the usage of Carnoy's solutions (with and without chloroform) induces lower recurrence rate when compared with further treatments. ${ }^{[12,24-26]}$

In 1992, American Food and Drug Administration (FDA) Compliance Policy Guide (chapter 4 subchapter $460)^{[27]}$ prohibited pharmaceutical compositions of therapeutic agents containing chloroform, as considered a carcinogenic compound. ${ }^{[24,25]}$ Indeed, this guidance promoted the replacement of chloroform and Carnoy's solution changed to the composition: 9-ml absolute ethanol, 3-ml acetic acid, and 1-g ferric chloride. ${ }^{[28]}$ Nevertheless, both Carnoy's solutions (with and without chloroform) are currently used in clinical practice as adjunctive for several surgical interventions, and the principal parameters evaluated are the recurrence of lesions. ${ }^{[1-17,24]}$ However, two aspects of such agent were not previously surveyed: (a) physicochemical properties of the solution and (b) effects of storage period on the features and formation of by-products.

In a recent systematic review, Al-Moraissi et al. ${ }^{[3]}$ found in 2,287 non-syndromic keratocystic odontogenic tumors recorded in 35 studies that relapse rates associated with treatment of these lesions were enucleation alone (23.1\%), enucleation with peripheral ostectomy (17.4\%), enucleation and Carnoy's solution (11.5\%), enucleation plus liquid nitrogen cryotherapy (14.6\%), marsupialization alone (32.3\%), decompression followed by residual cystectomy (14.6\%), and resection (8.4\%). Indeed, this highlights the role of Carnoy's solution as one of the main less invasive treatments. ${ }^{[3]}$

Physicochemical characterization of modified Carnoy's solution has never been realized up to this investigation. Although Puchtler et al. ${ }^{[2]}$ had investigated the chemical components of Carnoy's solution in 1968, that study did not consider the presence of ferric chloride as well as the presence/absence of chloroform, substances well known by maxillofacial surgeons. ${ }^{[25,26]}$ The isolated compounds featured in the present investigation depicted fundamental aspects to perceive the mechanism of action of Carnoy's solution in the treatment of maxillary aggressive odontogenic lesions.

Ethanol $\left(\mathrm{CH}_{2} \mathrm{H}_{5} \mathrm{OH}\right)$ presents the properties of a coagulative fixative that denature insoluble proteins in water at room temperature and extract phospholipids from cells without affecting the carbohydrates, ${ }^{[29,30]}$ principally when in major concentration in the solution (described as solvent). Chloroform $\left(\mathrm{CHCl}_{3}\right)$ enhances and accelerates ethanol penetration in the tissue. It is a compound with lipophilic nature that improves the dehydration of tissues by dissolving the lipids in membranes, favoring the action of ethanol in the process. ${ }^{[31-33]}$ Indeed, such feature may likely attain lower efficacy of Carnoy's solution without chloroform. This corroborates with the findings of Dashow's studies ${ }^{[17,24]}$ that demonstrated higher recurrence rates in patients submitted to adjunct therapy with Carnoy's solution without chloroform for the treatment of keratocystic odontogenic tumors. ${ }^{[24]}$ Authors also speculated that Food and Drug Administration (FDA-USA) should 
allow the use of Carnoy's solution with chloroform for clinical trials, because, in histology, chloroform is a solvent for lipids relatively inert in other tissues. ${ }^{[29]}$ The limit of occupational exposure to chloroform in an 8-hr shift is $2 \mathrm{ppm}\left(9.9 \mathrm{mg} / \mathrm{m}^{3}\right)$, and for buffered neutral formalin, it is $1 \mathrm{ppm}\left(1.2 \mathrm{mg} / \mathrm{m}^{3}\right)$. Moreover, formalin is known as a carcinogenic agent, whereas chloroform is classified as a likely carcinogenic compound. ${ }^{[32]}$ Such aspects may justify the use of chloroform within Carnoy's solution in relation to the possibility of the reduction in recurrence rates ${ }^{[26]}$ and lower occupational risk. ${ }^{[32]}$

Glacial acetic acid $\left(\mathrm{CH}_{3} \mathrm{COOH}\right)$ penetrates rapidly in tissues and has the role of preserving chromosomes through the coagulation of nucleic acids. ${ }^{[19]}$ Furthermore, this compound brakes the cross-links between proteins and releases hydrophilic radicals, swelling the tissue, thereby preventing the excessive shrinking and stiffening promoted by ethanol action. ${ }^{[34]}$

Ferric chloride $\left(\mathrm{FeCl}_{3}\right)$ is a brownish chemical agent with acidic and protein coagulating properties, which provides its characteristics as strong hemostatic agent. By the contrary of further known hemostatic agents, ferric chloride displays its effects through the chemical reaction with blood, regardless the action of normal hemostatic system. As most topical hemostatic agents are employed to control superficial bleeding, requiring normal hemostatic functions to achieve the effects, the addition of a local hemostatic agent that exempts the need for a normal hemostatic system may indeed improve the coagulative effect. $^{[35]}$

In 1928, the physicist Sir Chandrasekhara Venkata Raman observed and interpreted the phenomenon of inelastic scattering of light through the matter using a microspectroscopy technique, currently denominated as Raman effect. ${ }^{[36]}$ Raman spectroscopy is a valuable analytic technique able to assay the chemical composition of a variety of samples, such as fluids, cells, and tissues. Furthermore, it may detect a molecular "fingerprint" of different substrates useful for diagnosis and assessment of new therapies, thereby providing qualitative and quantitative information in a noninvasive high-resolution $(1 \mu \mathrm{m})$ experiment. $^{[36,37]}$

In this regard, the aim of this study was to characterize two formulations of Carnoy's solution with ferric chloride (with and without chloroform) employed in oral maxillofacial surgery, in order to survey their physicochemical and pharmacological properties, and further characterize the Raman spectra of these solutions along the time. To date, no investigations in our knowledge have characterized Carnoy's solution or demonstrated physicochemical alterations of such solution in presence or absence of chloroform over time.

\section{2 | MATERIALS AND METHODS}

\section{1 | Preparation of solutions}

The Carnoy's solutions used in this investigation were prepared by the same trained pharmaceutical, by using 6-ml absolute ethanol, 3-ml chloroform, 1-ml acetic acid and 1-g $\mathrm{FeCl}_{3} \cdot 6 \mathrm{H}_{2} \mathrm{O}$ (ferric chloride hexahydrate) to obtain an approximately $10-\mathrm{ml}$ final solution. ${ }^{[4,21]}$ To obtain Carnoy's solution without chloroform, the $3 \mathrm{ml}$ of chloroform was replaced by $3-\mathrm{ml}$ absolute ethanol. ${ }^{[17,23,28]}$

The solutions produced, as described above, have supersaturated concentration relative to the ferric chloride hexahydrate salt. We proceeded with the filtration of the samples using a $0.45-\mu \mathrm{m}$ syringe filter, which allowed to obtain solutions of Carnoy's with or without chloroform filtered. Thus, four types of solution were analyzed in the present study: unfiltered Carnoy's solution with chloroform, filtered Carnoy's solution with chloroform, unfiltered Carnoy's solution without chloroform, and filtered Carnoy's solution without chloroform.

\section{2 | Pharmacological characterization (density, pH, viscosity, and $\mathrm{Fe}^{3+}$ concentration)}

The pharmacological properties of Carnoy's solutions with and without chloroform determined were mass density and relative density (pycnometer, Prolab, Materials for Laboratory, São Paulo, Brazil), viscosity (viscometer, Viscotester 6L Thermo Haake-Thermo Fisher Scientific Inc., Germany), and $\mathrm{pH}$ (Benchtop pHmeter DM23, Digimed, Campo Grande, Brazil). ${ }^{[38]}$ Determination of $\mathrm{Fe}^{3+}$ concentration was undertaken by means of ultraviolet/visible (UV/Vis) spectroscopy (GENESYS $20 \mathrm{UV} / \mathrm{Vis}$ Spectrophotometer, Thermo Fisher Scientific Inc., Germany) by the reaction with potassium thiocyanate in aqueous solutions. ${ }^{[39]}$

\section{3 | Raman spectroscopy}

Spatial distribution of organic and inorganic components was evaluated through the relative intensities of peaks obtained in a Raman microspectrophotometer (Xplora, Horiba Scientific, Paris, France). An argon laser with 638-nm wavelength and 3.2-mW power were used along with 10x magnification lens (Olympus American Inc., London, UK) to obtain the focus. Solutions were adapted in optical buckets for standardization. Raman spectra were attained in the range between 200 and $3,500 \mathrm{~cm}^{-1}$ with 3 accumulations and $10 \mathrm{~s}$ acquisition time. The laser was employed in $10 \%$ total power, and the focus was obtained on the liquid surface. The acquisition of Raman 
spectra was conducted in the same temperature and pressure $\left(22^{\circ} \mathrm{C}\right.$ and $\left.1 \mathrm{~atm}\right)$ conditions. Ten milliliter of each solution was surveyed.

All components were assayed separately as well as possible combinations, in order to facilitate the process of identifying the peaks in the spectrum of the solution. Ferric chloride hexahydrate was dissolved in absolute ethanol, as the common solvent. All analyses were realized once a week for 4 weeks in order to detect possible alterations over time. The Raman spectra were acquired in LabSpec 6 software (Horiba) and further manipulated in OriginPro 9.0 software (OriginLab Co., Northampton, USA). They were processed with baseline correction, smoothing by polynomial method (SavitzkGolay) and peaks position/intensity identification by Gaussian and Lorentzian methods to ensure characterization and deconvolution of graphs. ${ }^{[40]}$

\section{4 | Statistical analysis}

The data were tabulated in Microsoft Excel ${ }^{\circledR}$, and the relative expressions were calculated as a percentage of the height, width, and area of each peak in relation to the total of existing peaks. Area/width ratios were used to standardize these measurements.After that, the values obtained were exported to the Statistical Packing for Social Sciences $\left(\mathrm{SPSS}^{\circledast}\right.$ ) version 17.0 software with a $95 \%$ confidence interval for the design of the multivariate analysis model (ANOVA-3-way followed by the posttest Bonferroni) to evaluate the interaction between the time, filtration, and

TABLE 1 Characterization of viscosity of Carnoy's solutions with and without chloroform in relation to water

\begin{tabular}{llll} 
& $\begin{array}{l}\text { Mean spreading } \\
\text { time }(\mathbf{s})\end{array}$ & $\begin{array}{l}\text { Density } \\
(\mathrm{g} / \mathbf{m l})\end{array}$ & $\begin{array}{l}\text { Viscosity } \\
(\mathbf{m P a} \cdot \mathbf{s})\end{array}$ \\
\hline Water & 7.24 & 0.99704 & 1 \\
\hline Carnoy's solution & 7.36 & 1.0805 & 1.1017 \\
$\begin{array}{l}\text { Carnoy's solution } \\
\text { without chloroform }\end{array}$ & 7.72 & 0.8862 & 0.9478 \\
\hline
\end{tabular}

chloroform factors in the heights, widths, areas, and relative area/width ratio of each of the observed peaks. For the graphical representation of significant associations, the means and standard deviations were depicted.

\section{3 | RESULTS}

\section{1 | Pharmacological characterization}

Relative density and viscosity of Carnoy's solution were influenced by the presence of chloroform, with higher density and viscosity than water when with chloroform. In its absence, lower viscosity was attained (Table 1). The pH of solutions was highly acidic during the evaluation. Carnoy's solution with chloroform $(\mathrm{pH}=0.12)$ was more acid than without chloroform $(p=.27)$. Turbidity was more observed in the presence of chloroform than without, starting from the seventh day after manipulation. Iron precipitation was detected in all nonfiltered solutions.

The assessment of $\mathrm{Fe}^{3+}$ concentration by UV/Vis spectroscopy exhibited a slight increase in ferric ions concentration over the 4 weeks survey. Besides, higher concentrations were attained in nonfiltered solutions (Table 2).

\section{2 | Raman spectroscopy}

The spectra of isolated compounds are described in Figure 1 . They were organized in order to identify peaks of each component of Carnoy's solutions with and without chloroform. The relative intensity of peaks was established in relation to the major peak of the compound, thereby determining very weak (vw), weak (w), medium (m), strong (s), and very strong (vs) peaks as well as shoulders (Table 3). Based on the identified peaks of isolated solutions as described, one may highlight characteristic peaks of the components in solutions with and without chloroform, depicted in Figure 2.

Thus, in Carnoy's solutions, the main peaks were absolute ethanol (433, 879, 1,047, 1,091, 1,273, and

TABLE 2 Concentration of $\left[\mathrm{Fe}^{3+}\right]$ by $\mathrm{UV} /$ Vis calculated by the line equation in calibration curve $\left(\mathrm{Abs}=0.1521 .\left[\mathrm{Fe}^{3+}\right]+0.0077\right)$

\begin{tabular}{|c|c|c|c|c|}
\hline & $\begin{array}{l}\text { Week } 1 \\
{\left[\mathrm{Fe}^{3+}\right](\mu \mathrm{g} / \mathrm{ml})}\end{array}$ & $\begin{array}{l}\text { Week } 2 \\
{\left[\mathrm{Fe}^{3+}\right](\mu \mathrm{g} / \mathrm{ml})}\end{array}$ & $\begin{array}{l}\text { Week } 3 \\
{\left[\mathrm{Fe}^{3+}\right](\mu \mathrm{g} / \mathrm{ml})}\end{array}$ & $\begin{array}{l}\text { Week } 4 \\
{\left[\mathrm{Fe}^{3+}\right](\mu \mathrm{g} / \mathrm{ml})}\end{array}$ \\
\hline Mean $(1,1 F, 2$, and $2 F)$ & 7.67 & 7.75 & 7.70 & 8.27 \\
\hline Mean $1 F$ and $2 F$ & 7.64 & 7.81 & 7.72 & 8.60 \\
\hline Standard deviation & 0.090 & 0.290 & 0.016 & 0.611 \\
\hline
\end{tabular}

Note. 1 = Carnoy's solution with chloroform non-filtered; $1 \mathrm{~F}=$ Carnoy's solution with chloroform filtered; 2 = Carnoy's solution without chloroform nonfiltered; $2 \mathrm{~F}=$ Carnoy's solution without chloroform filtered. 


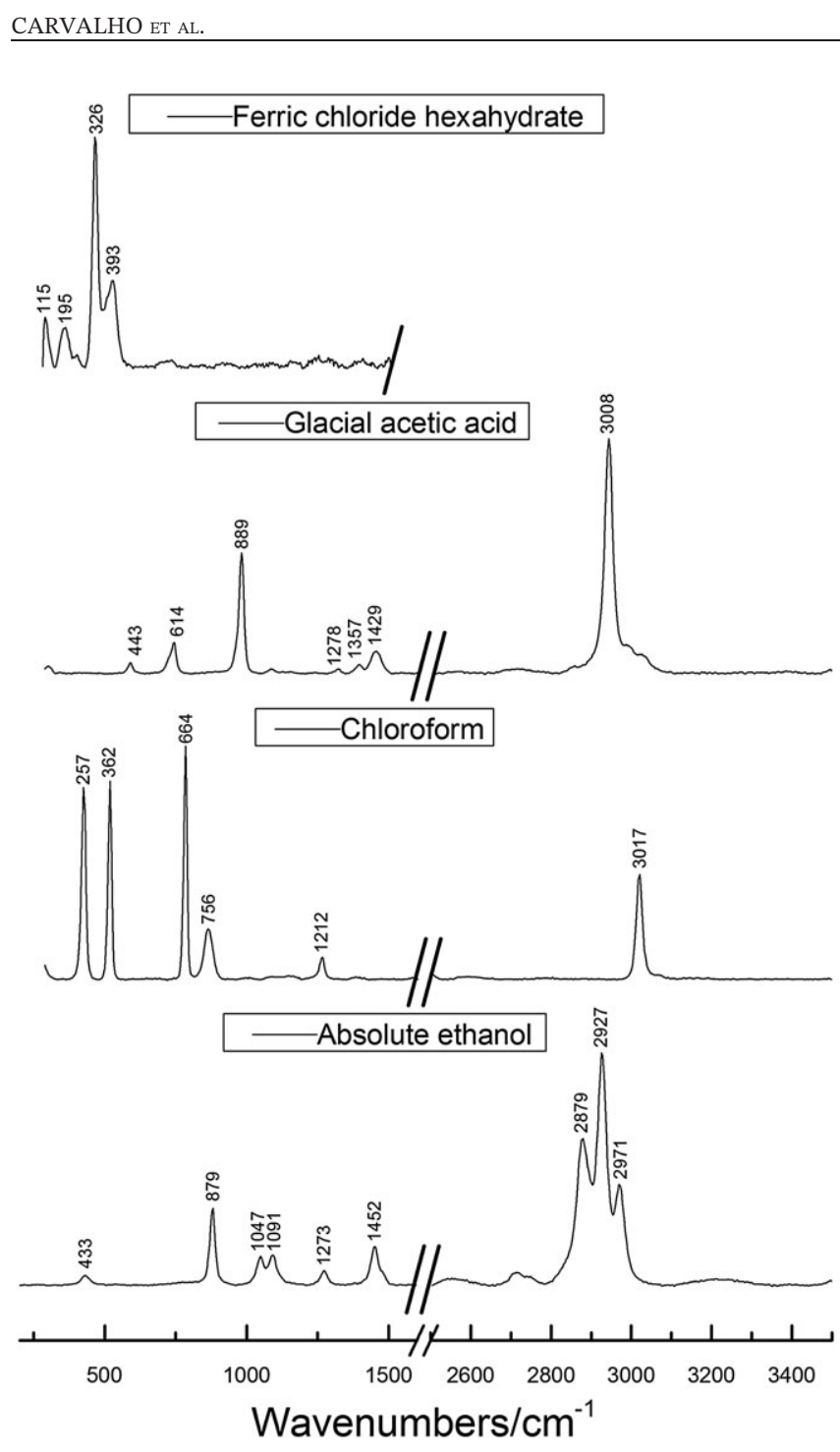

FIGURE 1 Spectra of components from Carnoy's solution with red laser $(638 \mathrm{~nm})$ compiled in OriginPro 9.0 software

$\left.1,452 \mathrm{~cm}^{-1}\right)$, acetic acid $\left(614 \mathrm{~cm}^{-1}\right)$, ferric chloride $\left(326 \mathrm{~cm}^{-1}\right)$, and chloroform $\left(257,362,664\right.$, and $756 \mathrm{~cm}^{-1}$; Figure 2).

\section{a. Filtration factor}

The filtration factor has little effect on the relative measurements of the peaks evaluated. Only peak area $879 \mathrm{~cm}^{-1}$ of absolute ethanol was significantly influenced by the filtration factor, with a significant increase in the mean area of this peak after filtration $(16.3 \pm 6.9 \%$ to $17.7 \pm 6.3 \%, p=.033$; Table 4 ).

\section{b. Chloroform factor}

The presence of chloroform was the main agent that influenced the heights of ferric chloride, acetic acid, and absolute ethanol.The peak height of ferric chloride $(21.30 \pm 0.13$ to $14.21 \pm 0.31, p=.027)$, the width
WI LEY-RAMAN

$(12.06 \pm 0.56$ for $7.90 \pm 0.08 p<.001)$, and area $(15.00 \pm 0.81$ to $12.66 \pm 0.21 \%, p<.001)$ were significantly decreased on the chloroform presence. Height, width, and area, respectively, of the peaks $433 \mathrm{~cm}^{-1}$ (3.38 \pm 0.08 for $1.60 \pm 0.19, p<.001 ; 13.60 \pm 0.56$ for $9.36 \pm 1.46$, $p<.001 ; 4.02 \pm 0.02$ for $2.42 \pm 0.01, p<.001$, respectively), $879 \mathrm{~cm}^{-1}(25.67 \pm 0.42$ for $11.11 \pm 0.83$, $p<.001 ; 13.19 \pm 1.13$ for $8.48 \pm 0.98, p<.001$; $22.93 \pm 1.32$ for $11.46 \pm 1.19, p<.001$, respectively), $1047 \mathrm{~cm}^{-1}(10.31 \pm 0.20$ for $5.02 \pm 0.17, p=.002$; $12.66 \pm 0.80$ for $9.02 \pm 0.64, p<.001 ; 11.92 \pm 1.06$ for 6 , $47 \pm 0.97, p<.001$, respectively), and $1452 \mathrm{~cm}^{-1}$ $(19.04 \pm 0.11$ for $9.89 \pm 0.76, p=.004 ; 14.29 \pm 3.03$ for $9,00 \pm 0.62, p=.003 ; 23.43 \pm 2.76$ to $13.10 \pm 0.13$, $p<.001$, respectively) decreased significantly by the presence of chloroform. Already the peaks $1,091 \mathrm{~cm}^{-1}$ $(11.85 \pm 0.25$ for $9.62 \pm 1.49, p=.002$ and $12.36 \pm 0.33$ for $7.53 \pm 0.93, p<.001$, respectively) and $1,273 \mathrm{~cm}^{-1}$ $(12.98 \pm 1.86$ for $6.79 \pm 0.09, p<.001$ and $7.67 \pm 0.21$ for $3.73 \pm 0.03, p<.001$, respectively) declined only in width and area of their peaks, respectively. The area/ width ratio of the $1,091 \mathrm{~cm}^{-1}$ peak of absolute ethanol increased significantly with the use of chloroform $(1.17 \pm 0.11$ to $1.42 \pm 0.21, p=.017$; Table 4$)$.

\section{c. Time factor}

The time factor significantly altered the height of the peak $756 \mathrm{~cm}^{-1}$ of chloroform from w1 $(4.63 \pm 0.09 \%)$ to $\mathrm{w} 2(5.85 \pm 0.06)$ and from that to $\mathrm{w} 3(4.13 \pm 0.33)$ and $\mathrm{w} 4$ $(4.53 \pm 0.19 \% ; p=.016)$, as well as the area of this peak of w1 $(7.11 \pm 0.34 \%)$ and $\mathrm{w} 2(8.97 \pm 0.29 \%)$ to w3 $(5.43 \pm 0.71 \%)$ and $\mathrm{w} 4(6.23 \pm 0.40 \% ; p=0.021)$. The area of the ferric chloride peak $\left(326 \mathrm{~cm}^{-1}\right)$ was also influenced by time dropping significantly from $\mathrm{w} 1(13.83 \pm 1.44 \%)$ to w2 (11.75 $\pm 2.32 \%)$ and w3 (11.92 $\pm 7.58 \%)$ and rising significantly in w4 $(14.42 \pm 2.70 \% ; p=.025)$. The peak height of acetic acid $614 \mathrm{~cm}^{-1}$ dropped significantly from w1 $(3.39 \pm 0.40 \%)$ and $\mathrm{w} 2(4.10 \pm 0.74 \%)$ to $\mathrm{w} 3$ $(2.96 \pm 0.41 \%)$ and W4 $(1.97 \pm 0.84 \% ; p=.004)$ and the area of this peak dropped significantly from w1 $(2.61 \pm 0.67 \%)$ and $\mathrm{w} 2(3.92 \pm 1.17 \%)$ to $\mathrm{w} 3(2.48 \pm 0.36 \%)$ and $\mathrm{w} 4$ $(2.45 \pm 0.33 \% ; p=.025)$. The area of the $433 \mathrm{~cm}^{-1}$ absolute ethanol peak increased significantly from w1 $(3.22 \pm 0.92 \%)$ and $\mathrm{w} 2(2.43 \pm 1.08 \%)$ to $\mathrm{w} 3$ $(3.39 \pm 1.13 \%)$ and $\mathrm{W} 4(3.00 \pm 1.17 \% ; p=.005$; Table 4$)$.

\section{4 | DISCUSSION}

In this study, viscosity and acidity of Carnoy's solution varied according to the presence of chloroform, with increasing viscosity in the order Carnoy's solution 
TABLE 3 Characteristic peaks of Carnoy's solutions components

\begin{tabular}{|c|c|c|c|c|c|c|c|}
\hline \multicolumn{8}{|c|}{ Raman spectroscopy } \\
\hline Peak & Intensity & Peak & Intensity & Peak & Intensity & Peak & Intensity \\
\hline 443.915 & vw & $257.199^{\mathrm{ab}}$ & $\underline{m}$ & 433.081 & $\mathrm{vw}$ & 115.32 & $\mathrm{w}$ \\
\hline 614.376 & $\underline{m}$ & $362.36^{* \mathrm{~b}}$ & $\underline{m}$ & 879.885 & s & 195.59 & $\mathrm{w}$ \\
\hline 889.81 & s & $664.798^{\mathrm{ab}}$ & $\underline{s}$ & $\underline{1,047.8}$ & $\underline{w}$ & $\underline{326.14}^{\mathrm{a}}$ & $\underline{s}$ \\
\hline$\underline{1,357.69}$ & $\underline{w}$ & $\underline{1,212.29}$ & $\underline{v w}$ & $\underline{1,273.53}$ & $\underline{v w}$ & & \\
\hline $1,429.79$ & $\mathrm{~m}$ & $\underline{3,017.73}^{\mathrm{ab}}$ & $\underline{s}$ & $1,452.3$ & $\underline{m}$ & & \\
\hline $2,941.1$ & vs & & & $\underline{2,879.01^{\mathrm{a}}}$ & $\underline{m} ; s h$ & & \\
\hline $3,008.95$ & $\mathrm{sh}$ & & & $2,927.34$ & s & & \\
\hline
\end{tabular}

Note. vw = very weak; $\mathrm{w}=$ weak; $\mathrm{m}=$ medium; $\mathrm{s}=$ strong; $\mathrm{vs}=$ very strong; $\mathrm{sh}=$ shoulder.

Underlined items may be identified, but due to overlapping, they do not characterize the "fingerprint" of isolated compounds in Carnoy's solution.

aCharacterizes the peaks of "fingerprint" identified in Carnoy's solution.

${ }^{\mathrm{b}}$ Specific peak of Carnoy's solution with chloroform.

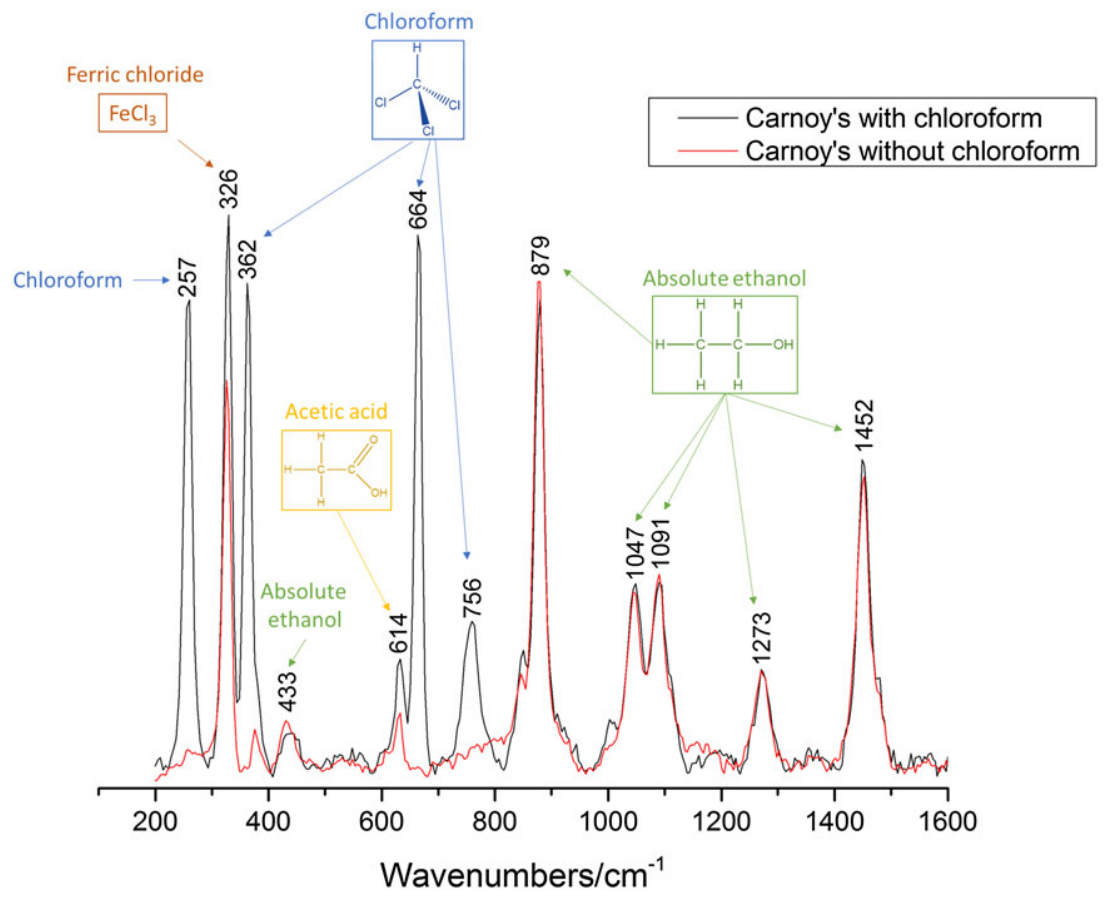

FIGURE 2 Spectra of components from Carnoy's solutions (with and without chloroform) with red laser (638 nm) compiled in OriginPro 9.0 software [Colour figure can be viewed at wileyonlinelibrary.com]

without chloroform, water and Carnoy's solution with chloroform, in addition to a discrete increase of $\mathrm{pH}$. Such $\mathrm{pH}$ values obtained may be explained by the presence of acetic acid, chloroform, ${ }^{[19,34]}$ and ferric chloride ${ }^{[35]}$ in composition. All of these components present acid feature when isolated. These findings apparently can be related to the idea that the Chloroform $\left(\mathrm{CHCl}_{3}\right)$ presence enhances and accelerates ethanol penetration in the tissue. It is a lipophilic nature compound that improves the dehydration of tissues by dissolving the lipids in membranes, favoring the action of ethanol in the process. ${ }^{[31-33]}$ Indeed, such feature may likely attain lower efficacy of Carnoy's solution without chloroform. This corroborates with the findings of Dashow's studies, ${ }^{[17,24]}$ which demonstrated higher recurrence rates in patients submitted to adjunct therapy with Carnoy's solution without chloroform for the treatment of keratocystic odontogenic tumors. ${ }^{[24]}$ Thus, as the chloroform presence reduces 
TABLE 4 Multifactorial analysis of time, chloroform, and filtration factors in the relative percentage of height, width, area, and area/width ratio of the relative percentage of the peaks in relation to the total of peaks found

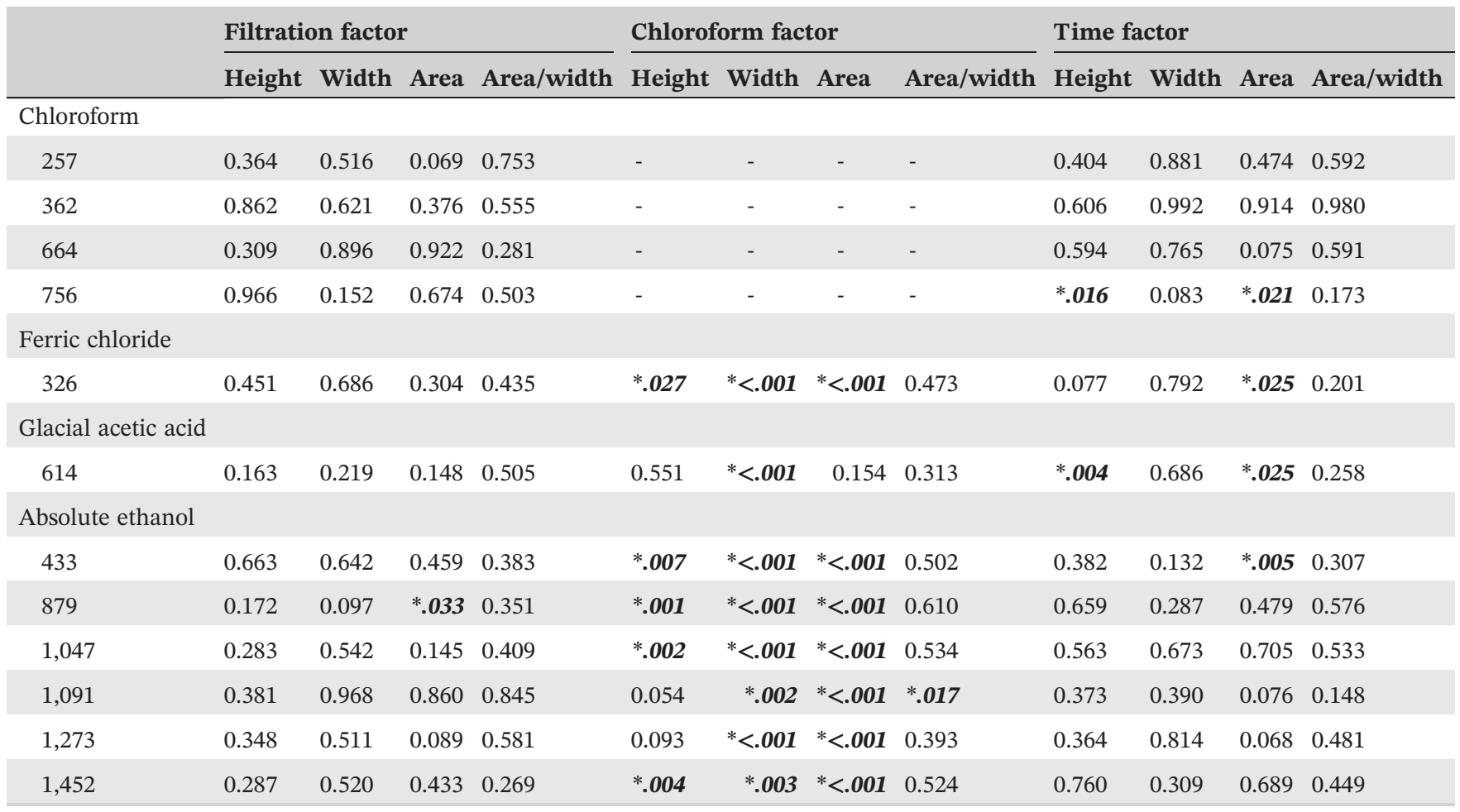

${ }^{*} p<0.05$; Multifactor analysis model ANOVA-3-way/Bonferroni. Data expressed as $p$ values.

Hyphens represent absence of values, once chloroform is not present in this section of the table.

the solution $\mathrm{pH}$ and the recurrence capacity, the authors believe that a more acidic $\mathrm{pH}$ can be an advantage for the Carnoy's solution in a clinical use context.

Concerning the determination of ferric chloride concentration, the present outcomes showed no difference among solutions during the days of investigation, both intrasolution and intersolution. Indeed, this result demonstrates the stability of Carnoy's solution with ferric chloride similarly to what was described by Puchtler et al. ${ }^{[29]}$ However, although this relatively adequate stability, the turbidity of the solution with chloroform from the seventh day after manipulation and the precipitation of ferric crystals in nonfiltered solutions need to be taken into consideration for the use of Carnoy's solution after some days after preparation. Indeed, this may alter the properties of solutions when applied in the tissues.

The present study findings reinforce the role of ferric chloride as a coagulative necrosis promoting agent, ${ }^{[35]}$ which from the therapeutic point of view may be strongly associated with low recurrence rates when Carnoy's solution is used in certain benign odontogenic neoplasms. ${ }^{[12,24-26]}$ In addition, it showed that the unfiltered Carnoy's solutions had a more available ferric chloride content than the filtered ones, which may be an important information for the orientation of the pharmacist to not filter the solution in order to present a greater saturation of the ferric chloride, in addition to inform the professional who will use the solution that the turbidity is a normal finding over time in Carnoy's solutions with chloroform.

There are no published papers that have indicated that the Carnoy's solution was handled and used on the same day or if it was stored and used after 7 days or more. According to our practice and what we observe, it is underlined that what happens is the first option. This may be justified by the fact that there are no studies comparing the effect of Carnoy's solution with different storage periods prior to its use.

Raman spectroscopy was used herein to survey the chemical composition of samples, as many materials possess characteristic Raman spectra, proving to be a reliable analytical method for several areas of science. Raman spectroscopy associated with microscopy is widely applied in the biological field, once it may provide important information regarding chemical composition with nondestructive sample preparation and without the water interference. Furthermore, this analyseis does not require vast preparation to obtain biochemical and structural information, ${ }^{[41]}$ thereby identifying possible degradation of Carnoy's solutions over time without affecting the samples.

Carnoy's solution as a tissue fixative agent was firstly analyzed by Meade et al., ${ }^{[42]}$ in which the authors verified 
the effects of chemical fixatives in human cells through Raman spectroscopy. ${ }^{[42]}$ However, there are no reports about the characterization of Carnoy's solution incorporated with ferric chloride (with and without chloroform), applied as cauterizing agent for oral and maxillofacial surgery, surveyed by Raman spectroscopy.

In the present investigation, the laser with 638-nm wavelength was undertaken, although an infrared laser with $785-\mathrm{nm}$ wavelength was used by Meade et al. ${ }^{[42]}$ Although this study has not used the same laser of the previously cited authors, the data obtained by Meade et al. ${ }^{[42]}$ (666, 757 [chloroform], 881, 1,050, 1,093, 1,274, and $1,452 \mathrm{~cm}^{-1}$ [absolute etanol]) were similar to the ones observed in Figure 2. This can be explained by the fact that both lasers in red/infrared region may justify the similar results obtained. In addition, this investigation detected new peaks that had not been previously reported; specifically, the peaks at 257,362 (chloroform), and $326 \mathrm{~cm}^{-1}$ (ferric chloride) were also detected in the present spectra. These peaks contrast the modified Carnoy's solution from traditional Carnoy's solution and identify ferric chloride in the solutions. Spectroscopic alterations on the behavior of peaks 257, 362 (chloroform), and $326 \mathrm{~cm}^{-1}$ (ferric chloride) were found, suggesting an instability of the solution in the second week after preparation and posterior return to the stability condition in the third week (Figure 3). This may likely explain the turbidity of the solution with chloroform after 7 days. Such behavior did not occur intensely in the solution without chloroform (Figure 3). Moreover, the pattern observed in filtered and nonfiltered solutions were contrasting regardless the period of evaluation (Figure 4). Indeed, such event might be explained by high saturation of ferric chloride in nonfiltered solution, as, in temperatures lower than $125{ }^{\circ} \mathrm{C}$ and acidic media, the formation of iron oxide or iron oxide-hydroxide may occur precipitating in less than $6 \mathrm{hr}^{[43,44]}$

Statistical analysis of Raman spectra (considering the assessment of height, width, area, and area/width ratio of isolated peaks) of solutions' components have evidenced significant alterations on filtration, chloroform, and time factors. Regarding filtration, only absolute ethanol peak $\left(879 \mathrm{~cm}^{-1}\right)$ presented statistical difference $(p<.05$; Table 4). Stability of further peaks ( $p>.05$ ) suggests that filtration factor seems not affecting the stability of solutions. Concerning chloroform factor, peaks of ferric chloride $\left(326 \mathrm{~cm}^{-1}\right)$, acetic acid $\left(614 \mathrm{~cm}^{-1}\right)$, and absolute ethanol (433, 879, 1,047, 1,091, 1,273, and 1,452 $\mathrm{cm}^{-1}$ ) suffered significant alteration $(p<.05)$. Such modifications suggest that the presence of chloroform attains higher instability for the solution, as observed by chloroform-containing solutions, which depicted turbidity after long periods.

Regarding the time factor, chloroform peak $\left(756 \mathrm{~cm}^{-1}\right)$, ferric chloride $\left(326 \mathrm{~cm}^{-1}\right)$, acetic acid

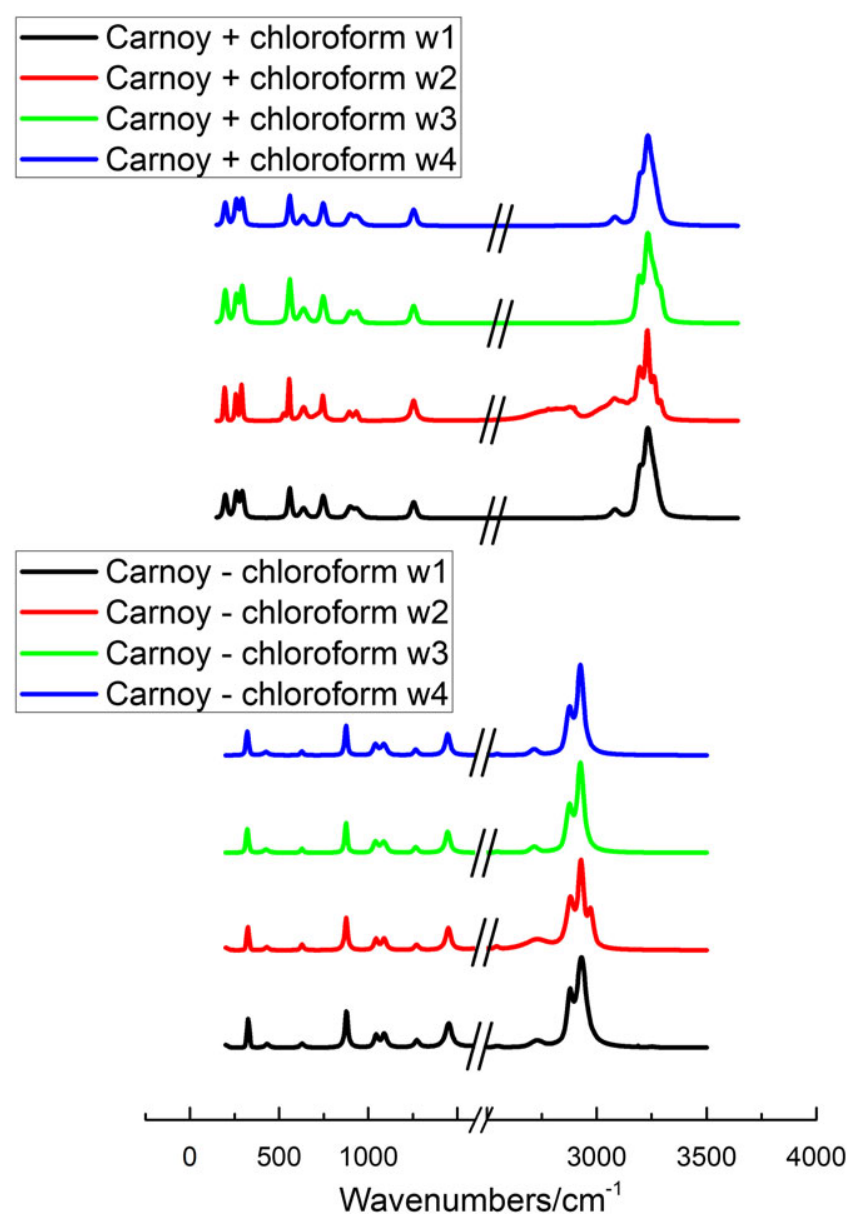

FIGURE 3 Spectra of Carnoy's solution with chloroform in weeks 1, 2, 3, and 4 [Colour figure can be viewed at wileyonlinelibrary.com]

(614 $\left.\mathrm{cm}^{-1}\right)$, and absolute ethanol $\left(433 \mathrm{~cm}^{-1}\right)$ showed significant differences $(p<.05$; Table 4$)$. Peaks from chloroform and ethanol were modified in only one peak from each component, which likely shows no noteworthy alteration for these components in solutions over time. Conversely, ferric chloride $\left(326 \mathrm{~cm}^{-1}\right)$ and acetic acid $\left(614 \mathrm{~cm}^{-1}\right)$ attained more alterations over time. This may have a potential correlation with iron precipitation and volatilization of components over time. Clinical trials employing Carnoy's solution in oral and maxillofacial surgery only cited that the solution was prepared for that specific moment, but there is no information if the solution should be discarded right after using, or rationale based on alterations on its properties and local effects. The present investigation is the first to assay the "aging" of Carnoy's solutions in normal storage conditions.

This study showed the long-term stability of Carnoy's solution. Such information is important for the clinician because the practitioner can use the solution after storage. Indeed, there will likely have no significant changes on the clinical effect of the solution when used as an 

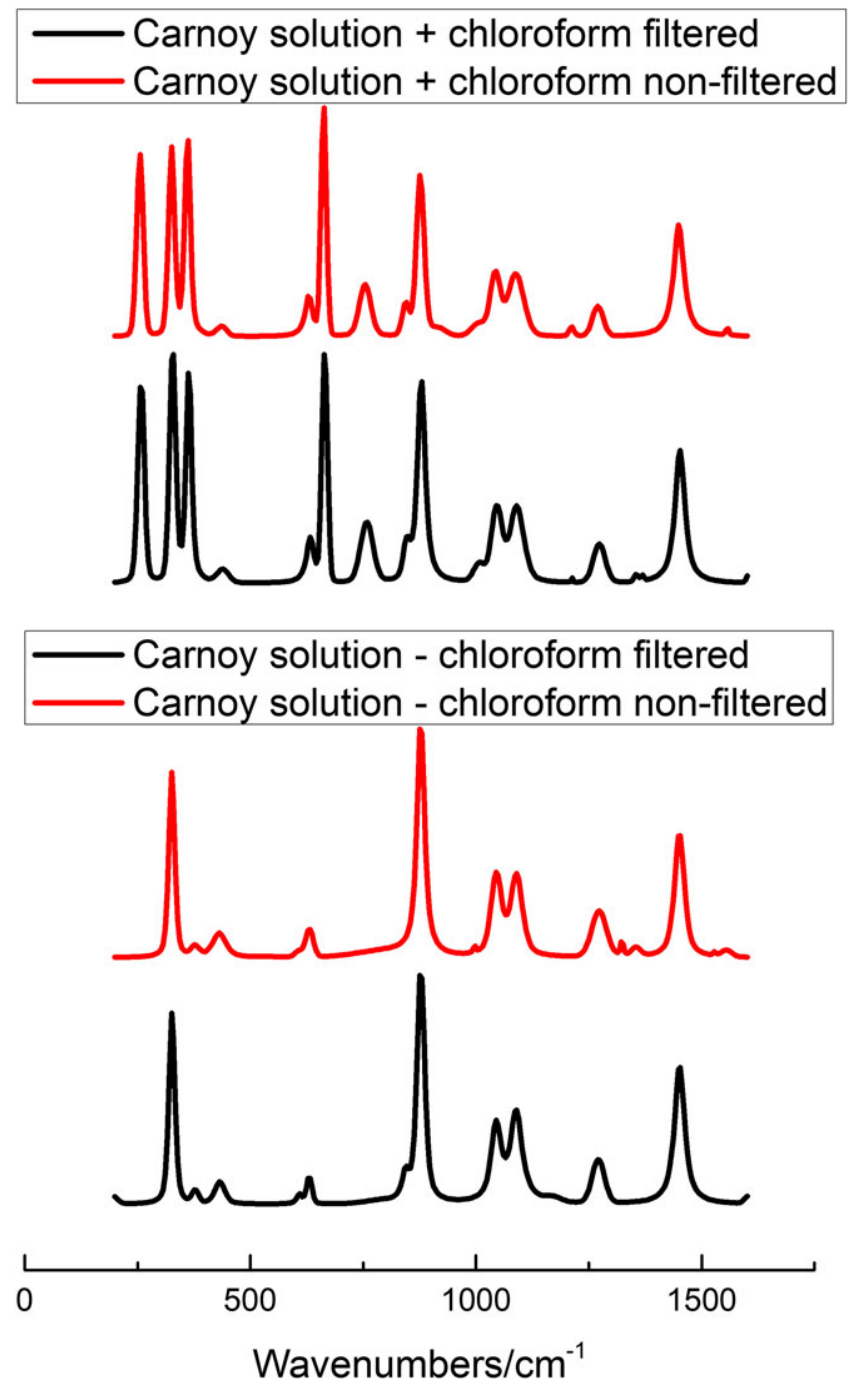

FIGURE 4 Spectra of Carnoy's solutions with and without chloroform filtered and nonfiltered [Colour figure can be viewed at wileyonlinelibrary.com]

adjuvant therapy on different days up to 6 days after preparation.

\section{5 | CONCLUSIONS}

The absence of chloroform in solution may affect the performance of the solution due to the reduction of viscosity and ethanol penetration in tissues. Overall, Carnoy's solutions are acidic, stable in the initial 7 days, and prone to suffer alterations in the formulation with chloroform after the seventh day (turbidity) as well as iron precipitation in the container when used without filtering.

\section{CONFLICT OF INTEREST}

The authors declared that they have no conflict of interest.

\section{ORCID}

Francisco Samuel Rodrigues Carvalho (i) http://orcid.org/ 0000-0002-3142-1268

\section{REFERENCES}

[1] F. W. G. Costa, E. C. S. Soares, S. H. B. Batista, RSBO. 2010, $7(2), 208$

[2] F. W. G. Costa, G. A. C. Brito, R. M. A. Pessoa, E. C. S. Soares, J. Appl. Oral. Sci. 2011, 19(6), 604.

[3] E. A. Al-Moraissi, A. A. Dahan, M. S. Alwadeai, F. O. Oginni, J. M. Al-jazmali, A. S. Alkhutari, N. H. Al-Tairi, A. A. Almaweri, J. S. Al-Sanabania, J. Craniomaxillofac. Surg. 2016; Oct 31. pii: S1010-5182(16)30258-X. https://doi.org/ 10.1016/j.jcms.2016.10.013. [Epub ahead of print].

[4] R. A. Voorsmit, P. J. Stoelinga, U. J. van Haelst, J. Maxillofac. Surg. 1981, 9(4), 228.

[5] P. J. Stoelinga, F. B. Bronkhorst, J. Craniomaxillofac. Surg. 1988, 16(4), 184.

[6] R. Dammer, H. Niederdellmann, P. Dammer, M. NueblerMoritz, Br. J. Oral. Maxillofac. Surg. 1997, 35(1), 46.

[7] I. Nish, G. Sandor, S. Weinberg, Plast. Surg. 1997, 5(3), 161.

[8] H. T. Chow, Oral. Surg. Oral. Med. Oral. Pathol. Oral. Radiol. Endod. 1998, 86(5), 573.

[9] M. Chiapasco, A. Rossi, J. J. Motta, M. Crescentini, J. Oral. Maxillofac. Surg. 2000, 58(9), 942; discussion 9.

[10] P. J. Stoelinga, Int. J. Oral. Maxillofac. Surg. 2001, 30(1), 14.

[11] Y. F. Zhao, J. X. Wei, S. P. Wang, Oral. Surg. Oral. Med. Oral. Pathol. Oral. Radiol. Endod. 2002, 94(2), 151.

[12] T. A. Morgan, C. C. Burton, F. Qian, J. Oral. Maxillofac. Surg. 2005, 63(5), 635.

[13] D. Chirapathomsakul, P. Sastravaha, P. Jansisyanont, Oral. Surg. Oral. Med. Oral. Pathol. Oral. Radiol. Endod. 2006, 101(1), 5; discussion 10

[14] M. Gosau, F. G. Draenert, S. Muller, B. Frerich, R. Burgers, T. E. Reichert, O. Driemel, Clin. Oral. Investig. 2010, 14(1), 27.

[15] J. L. Schussel, R. T. Stramandinoli, J. L. Dissenha, L. F. Avila, L. M. Sassi, J Contemp Dent Pract. 2011, 12(2), 100.

[16] O. Ribeiro Junior, A. M. Borba, C. A. Alves, M. M. de Gouveia, F. L. Coracin, J. Guimaraes Junior, Oral. Dis. 2012, 18(6), 548.

[17] J. Dashow, J. I. Helman, S. P. Edwards, J. McHugh, B. B. Ward, J. Oral. Maxillofac. Surg. 2013, 71(9), e4.

[18] N. Wuscher, Rev. Fr. Histotechnol. 1999, 12(1), 9.

[19] J. R. Baker. Principles of biological microtechnique; a study of fixation and dyeing. London: Methuen; 1958.

[20] R. Zollinger, A. R. Moritz, J. Nerv. Ment. Dis. 1933, 78(1), 86.

[21] E. C. Cutler, R. Zollinger, Am. J. Surg. 1933, 19(3), 411

[22] R. A. Voorsmit, Ned. Tijdschr. Tandheelkd. 2010, 117(5), 278.

[23] J. Ecker, R. T. Horst, D. Koslovsky, J. Oral. Maxillofac. Surg. 2016, 74(2), 278. 
[24] J. E. Dashow, J. B. McHugh, T. M. Braun, S. P. Edwards, J. I. Helman, B. B. Ward, J. Oral. Maxillofac. Surg. 2015, 73(11), 2132.

[25] E. A. Al-Moraissi, M. A. Pogrel, E. Ellis 3rd., J. Oral. Maxillofac. Surg. 2016, 74(10), 1974.

[26] Y. Y. Leung, S. L. Lau, K. Y. Tsoi, H. L. Ma, C. L. Ng, Int. J. Oral. Maxillofac. Surg. 2016, 45(9), 1154.

[27] US Food and Drug Administration, Section 460.200, in FDA Compliance Policy Guides, Food and Drug Administration, Washington, DC 1992, 219.

[28] J. Hellstein, T. Hopkins, T. Morgan, Oral Surg Oral Med Oral Pathol Oral Radiol Endod. 2007, 103(4), 24.

[29] H. Puchtler, F. Sweat Waldrop, H. M. Conner, M. S. Terry, Histochemie. 1968, 16(4), 361.

[30] H. Puchtler, F. S. Waldrop, S. N. Meloan, M. S. Terry, H. M. Conner, Histochemie. 1970, 21(2), 97.

[31] D. A. Luz, U. Ribeiro Jr., C. Chassot, E. S. F. S. Collet, I. Cecconello, C. E. Corbett, Histopathol. 2008, 53(6), 740.

[32] A. R. Dias, M. A. Pereira, E. S. Mello, B. Zilberstein, I. Cecconello, U. Ribeiro Junior, Gastric Cancer. 2016, 19(1), 136.

[33] C-J. Tsai. Comparing dna damage caused by formaldehyde, glutaraldehye, Carnoy's and methacarn in cancer tissue fixations. Thesis of Bowling Green State University; 2006.

[34] J. B. Carnoy. La biologie cellulaire; étude comparée de la cellule dans les deux règnes. Lierre; Paris: J. Van In \& Cie; O. Doin; 1884.

[35] S. Nouri, M. R. Sharif, S. Sahba, Trauma Mon. 2015, 20(1), e18042.

[36] B. Kann, H. L. Offerhaus, M. Windbergs, C. Otto, Adv. Drug Delivery Rev. 2015, 89, 71.
[37] K. Kong, C. Kendall, N. Stone, I. Notingher, Adv. Drug Delivery Rev. 2015, 89, 121.

[38] A. N. D. V. Sanitária, Farmacopeia Brasileira, Anvisa, Brasília 2010, 546.

[39] R. P. Buck, S. Singhadeja, L. B. Rogers, Analytic Chem. 1954, 26(7), 1240

[40] J. K. Kauppinen, D. J. Moffatt, H. H. Mantsch, D. G. Cameron, Appl. Spectrosc. 1981, 35(3), 271.

[41] H. J. Butler, L. Ashton, B. Bird, G. Cinque, K. Curtis, J. Dorney, K. Esmonde-White, N. J. Fullwood, B. Gardner, P. L. MartinHirsch, M. J. Walsh, M. R. McAinsh, N. Stone, F. L. Martin, Nat. Protoc. 2016, 11(4), 664.

[42] A. D. Meade, C. Clarke, F. Draux, G. D. Sockalingum, M. Manfait, F. M. Lyng, H. J. Byrne, Anal. Bioanal. Chem. 2010, 396(5), 1781.

[43] P. A. Riveros, J. E. Dutrizac, Hidrometallurgy. 1997, 46, 85.

[44] J. E. Dutrizac, P. A. Riveros, Mettalurgical and Materials Transactions B. 1999;(B), 993.

How to cite this article: Carvalho FSR, Feitosa VP, da Cruz Fonseca SG, et al. Physicochemical and rheological characterization of different Carnoy's solutions applied in oral and maxillofacial surgery. J Raman Spectrosc. 2017;48:1375-1384. https://doi. org/10.1002/jrs.5227 